\title{
Acute Marginal Artery
}

National Cancer Institute

\section{Source}

National Cancer Institute. Acute Marginal Artery. NCI Thesaurus. Code C102285.

The arteries that arise at the junction of the proximal and mid-right coronary artery conduit segments. 